\title{
The Usage of Non-Biodlegradable Packaging Materials, Recycling Strategies and Impacts on the Environment: the Case of Bahrain
}

Arpita Dutta

\section{ABSTRACT}

The increased usage of non-biodegradable packaging materials is an integral part of our modern life and they are used in many daily activities. Generally, plastics are synthesized from non-renewable sources and are mostly not biodegradable, while waste plastics are the cause of many of the serious environmental problems the world faces today. This study investigated consumer behaviour and perceptions related to the increased use of plastic bags in transporting household goods from shops. Specifically, the study identified the status and effectiveness of the use of non-biodegradable packaging methods amongst retailing establishments (cold stores and super markets) in the Kingdom of Bahrain in terms of usage, recycling strategies adopted, disposal, the problems encountered and impact on the environment. A descriptive study research method was used in this study. The rese archer also use df fve point Likert-like scales in the study. The respondents strongly agreed that there is high usage of plastic bags in the Kingdom of Bahrain. The reasons given for this included durability, cheaper prices, lighter than other alternatives and easy storage. The respondents moderately agreed that recycling strategies adopted by both the retail establishments and the consumers are in place in the Kingdom of Bahrain but indiscriminate use and disposal of these plastic carrier bags does pose a significant environmental threat to the country. Again, the study found that since most plastic waste is disposed of in landfill sites where, although not visible, bags are nevertheless coming to the surface as debris and are affecting marine life as well as being ingested by animals like camels. In addition, the conditions within landfills are causing the chemicals contained within the plastic to become more readily available to the environment and this is a particular concern in a small island like the Kingdom of Bahrain, where landfill management is not as closely monitored as in the developed countries. Plastic carrier bags were found to be favoured in transporting high-risk food products to avoid possible cross contamination. Consumers' perceptions and usage behaviours in connection with respective government's policies and implementation of recycling systems could be highly decisive in reducing the eco-impact of plastic and paper shopping bags.

Keywords: disposal to landfill, plastic bags, recycle, reduce, reuse, usage

\section{Introduction}

In recent years, as a result of changes in people's consumption patterns, a large amount of waste plastic has been added to municipal solid waste (MSW) facilities and has caused serious environmental concerns. Among other materials, a huge range of oil-based polymers is currently used in packaging applications. They are largely nonbiodegradable and particularly difficult to recycle or reuse due to mixed levels of contamination and complex composites. Almost all consumer goods purchased in everyday life come with packaging, which fulfils at least one of the following functions:

- to provide protection from physical damage, contamination and deterioration;

- to give sales appeal;

- to ensure the product identity is easily recognizable;

- to give information about the product;

- to optimize distribution and storage costs and

- to provide consumer convenience and safety. 
The Usage of Non-Biodegradable Packaging Materials, Recycling Strategies and Impacts on the Environment: the Case of Bahrain To cater to the different shopping needs of the people, there are many types of shopping bags available in the market. A variety of raw materials and technologies are employed to produce them. The most popular ones are plastic and paper bags. Plastic bags are made from non-renewable resources, where the main ingredients used are petroleum and natural gas. Polyethylene - high density and low density, linear low-density polyethylene are the raw materials generally used for the manufacture of plastic bags (Lajeunesse, 2004). The shopping bags used by supermarkets are ideally produced from LLDPE to obtain the desired thickness and glossy look. If one needs very thin and gauzy bags, then LDPE variants, which are light weight for transporting household goods from street shops, would be an ideal choice (Ellis et al., 2005). Plastic bags seem to be slender and light and hence are easy to carry. For the Arlington, Virginia-based American Plastics Council, plastic bags are cheap to produce and have been used at as high as $80 \%$ of all grocery and convenience store markets (Roach, 2003). Both plastic and paper bags are used by many people for shopping needs, although the frequency and percentage of use differs between individuals. This phenomenon appears to contradict contemporary public policy to ensure sustainable development (Ritch, Brennan \& Macleod, 2009). At first glance, the figures do seem startling with the total number of free carrier bags distributed by retailers reaching eight billion annually (WRAP, 2005). The average household is estimated to use around 400 carrier bags each year (Hay, 2010). The perceived impact of these bags include the consumption of non-renewable esources to resources to manufacture a recovery rates at end of life and high visibility and ecological impacts as litter (Lewis, Verghese \& Fitzpatrick, 2010). In addition, plastic carrier bag concerns have been raised as they have now come to be seen as a symbol of a modern ecological crisis due to concerns over waste management (Hawkins, 2001).

Bahrain is one of the largest consumers of goods and services in the world per capita and, hence, the country can be considered as a contributor to environmental degradation. If businesses in the country are willing to switch to sustainable packaging by using reusable cloth or plastic bags, their overall

footprint will reduce, greatly lowering the negative environmental impact. Retail establishments have taken voluntary measures to reduce the numbers of plastic carrier bags handed out at supermarkets, such as placing plastic carrier bags under the till out of the customers' sight, forcing customers to ask for them rather than having free access (WRAP, 2009). However, the effectiveness of this measure is considered questionable. Furthermore, it has been suggested that come symbolic of a "throw away" society and is readily held up to emphasize the message of sustainability and the link between behaviour and impact on the environmen possibly without justification (Williams, 2004).

The environmental problems associated with plastic bag use include littering and associated indiscriminate waste (e.g. bags escaping from landfill) (Smith, 2004). Disposal is closely linked to consumer behaviour, highlighting resource consumption issues that include reduction, reuse and recycling as combative measures. Plastic degradability issues relating to littering and resource use are also of significance, particularly concerning littering of the marine environment However, those in support of plastic carrier bags argue that plastic bag litter accounts for just $0.03 \%$ of all litter in the UK. As plastic bags find their way into landfill facilities, other concerns are raised as they take between 400-1,000 years to break down and may require light energy to do so. In addition, leaching of toxic chemicals resulting from the breakdown of these materials have the potential to disrupt hormone levels in animals within the food chain and may be passed to humans (Aldred, 2007) in various ways.

2. Research Design

Both qualitative and quantitative methods have been used in this research. The study is descriptive in nature and made use of random sampling. A five point Likert-type survey questionnaire wa used to obtain the data supported by focus group discussions. The type of the questions included in the research required finite responses and were clearly delineated, which enabled the respondents to recall issues easily and make fast decision regarding the popularity and frequency of the use of non-biodegradable packaging methods amongs retail establishments in Budaiya, Kingdom of

The Usage of Non-Biodegradable Packaging Materials, Recycling Strategies and Impacts on the Environment: the Case of Bahrain

Bahrain, as well as problems encountered in the use of biodegradable packaging methods.

The respondents of the study were the managers, supervisors and customers of three supermarkets and cold stores located in the Budaiya area of the Kingdom of Bahrain. The use of only three types of bags is considered in this study: oxo-biodegradable bags; biodegradable bags and thin coloured plastic bags.

3. Results and Discussion

Most respondents strongly agreed, with average mean response of 4. 59, that there is high usage of plastic bags in the Kingdom of Bahrain. These carrier bags are generally provided free of charge, which is a prime reason for the shoppers to use these bags excessively. The same adjectival rating of strongly agreed is also given by the respondents on durability, cheaper price, lighter than other alternatives and easy storage and being hygienic. Respondents said they use the single use thin plastic bags whenever they forget to bring along their reusable ones. Another reason for the high number of plastic bag in use was noted to be that many respondents reported that they are not interested in acquiring any of the available alternatives like reusable bags for life, woven reusable bags or cotton reusable bags because these are costlier options. In addition, the type of shopping trip is also another factor that determines the bag type they will likely use.

On lack of alternative packaging methods in retail establishments, the cold stores customers strongly agreed. One reason for this might be that the shop owners, in the absence of any type of penalties imposed by the government, resorted to the use of the cheapest bags possible and, also, most cold store customers were unaware of the legal and social cost dimensions to plastic bag use in the absence of adequate and accurate information. However, the study found that the managers, supervisors and high proportion of consumers who visited the supermarkets are aware about the environmental impact of thin plastic bags and preferred buying alternative bags for grocery shopping. The respondents had mixed feelings regarding continuation of the use of plastic bags without any kind of governmental interventions. The cold stores strongly agreed that usage of plastic bags should continue.

The average adjectival rating of agree (3.73) is given by the respondents in terms of high frequency of single use thin plastic bags given to the customers. The relatively good perceptions of the respondents like strongly agreed seem to be because of the shopping trips made frequently to the retail establishments. The respondents rarely used single use thin plastic bag for repeated shopping trips as they are given free of charge in every visit. This happens because, in a situation of no actual penalties, the shop owners of cold stores resorted to the use of the cheapest bags. Secondly the study also found that, most consumers of cold stores were unaware of the legal and social cost dimensions to plastic bag use in the absence of adequate and accurate information on the subject.

However, in the case of supermarkets, there is sale and reuse of alternative bags like canvas or woven bags, although not often. The reason might be that there is regular promotion of the use of reusable bags by displaying alternative bags and suggesting them to the consumers during checkout. This type of intervention involves putting some amount of pressure on the consumers to buy them and bring the same bags for every shopping trip. It is clear from the study that this class of consumers is more interested in being environmentally friendly. Most respondents have strongly agreed and, with an average mean response of 4.59 , that there is high usage of plastic bags in the Kingdom of Bahrain These carrier bags are generally provided free of charge, which is a prime reason for the shoppers to use these bags excessively. The same adjectival rating of strongly agreed is also given by the respondents on durability, cheaper price, lighter than other alternatives and easy storage and being hygienic. Respondents said they use the single use thin plastic bags whenever they forget to bring along their reusable ones. Another reason for the high number of plastic bag in use was, it was noted, because many respondents reported that they are not interested in acquiring any of the available alternatives like reusable bags for life, woven reusable bags or cotton reusable bags, because these are costlier options. As also found in another study (Hopewell, Dvorak \& Kosior, 2009), the reuse rate of plastic bags indicated that consumers rarely use plastic carrier bags for repeated shopping 
The Usage of Non-Biodegradable Packaging Materials, Recycling Strategies and Impacts on the Environment: the Case of Bahrain trips in line with similar studies (WRAP, 2015), the frequency of conventional carrier bags reuse could be encouraged with the right strategy. In addition, the type of shopping trip is also another factor that determines the bag type they will likely use. When making purchases such as raw meat and other high risk food products, the customers tend to avoid possible cross contamination and plastic carrier bags are used.

On the lack of alternative packaging methods in retail establishments, the cold stores strongly agreed that the shop owners, in the absence of any type of penalties imposed by the government, resorted to the use of the cheapest bags and also most cold store customers were unaware of the legal and social cost dimensions to plastic bag use in the absence of adequate and accurate information. However, the study found that the managers, supervisors and high proportion of consumers who visited the supermarkets are aware of the environmental impact of thin plastic bags and preferred buying alternative bags for grocery shopping. A study found that the most common reason provided for the use of plastic carrier bags was the respondent forgetting to take their reusable bags during subsequent shopping trips (WRAP, 2005). In addition, providing the plastic carrier bags free of charge may be an additional factor that hinders the campaign on alternative bags use gaining wider acceptance. The respondents had mixed feelings regarding continuation of the use of plastic bags without any kind of governmental interventions. The cold stores strongly agreed that usage of plastic bags should continue.

The average adjectival rating of agree (3.73) is given by the respondents in terms of high frequency of single use thin plastic bags given to the customers. The relatively high proportion of respondents answering strongly seems to be because of the shopping trips made frequently to the retail establishments. The respondents rarely used single use thin plastic bags for repeated shopping trips as they are given free of charge on every visit. This happen penalties, the shop owners of cold stores resorted to the use of the cheapest bags. Secondly, the study also found that most consumers of cold stores were unaware of the legal and social cost dimensions to plastic bag use in the absence of adequate and accurate information on the subject.
However, in the case of supermarkets, there is sale and reuse of alternative bags like canvas or woven bags, although not often. The reason for this might be that there is regular promotion of the use of reusable bags by displaying alternative bags and suggesting them to the consumers during checkout. These types of intervention are putting some amount of pressure on the consumers to buy them and bring the same bags for every shopping trip. It is clear classes of consumers are more interested in being environmentally friendly.

On average, the respondents moderately agreed with a mean score of 3.22 that recycling strategies adopted by both the retail establishments and the consumers are in place in the Kingdom of Bahrain The average adjectival rating of agree (4.19) is given by the respondents that the indiscriminate use and disposal of these plastic carrier bags does pose a significant environmental threat to the country. In the absence of any enforcement of legislatio by the government, environmental degradation is happening at a rapid pace. A majority of consumer claim to reuse carrier bags for a number of differen purposes or picking up pet waste or lining trash cans but rarely used them for repeated shopping trips. However, most of the respondents agreed that they are unaware of any form of plastic carrie bag recycling at the store. This finding supports the earlier claim that the vast majority of plastic carrier bags end up being disposed of with general domestic waste and ultimately find their way into landfill sites (Aldred, 2007). This finding did add to the issue with regard to the indiscriminate waste problems associated with the escape of plastic carrier bags as litter (Smith, 2004). In addition, the disposal of plastic carrier bags to landfill sites poses a significant environmental burden when including issues relating to production and resource use (WRAP, 2010). Some retail establishments are working continuously on improvement to the quantity and quality of recycling by promoting the re-use, recycling and recovery of plastics, to whic the consumers of both cold and supermarkets gave the adjectival rating of moderately agree (2.86). This implies that the cold stores and supermarkets are not promoting any kind of recycling programmes, plastic bags. All the respondents disagreed that Bahrain has a recycling plant which can turn plastic although there are drop-off points for unwanted
The Usage of Non-Biodegradable Packaging Materials, Recycling Strategies and Impacts on the Environment: the Case of Bahrain bags into desirable products and that the government of Bahrain is regularly promoting the use of recycling programmes all over the country.

\begin{tabular}{|l|c|c|c|c|c|}
\hline Indicators & Supermarket & Cold Store & Consumers & Average & Interpretation \\
\hline $\begin{array}{l}\text { Retail establishments are trying to look } \\
\text { beyond making short term gains and } \\
\text { looking at the long term impact they are } \\
\text { having on the natural world with particular } \\
\text { emphasis on preserving the capability of } \\
\text { the environment to support human life. }\end{array}$ & 3.29 & 2.50 & 4.05 & 3.28 & Neither \\
\hline $\begin{array}{l}\text { Responsible decisions of the retail } \\
\text { establishment reduce the business' negative } \\
\text { impact on the environment and, thereby, } \\
\text { promote environmental sustainability. }\end{array}$ & 4.00 & 1.35 & 3.86 & 3.07 & Neither \\
\hline $\begin{array}{l}\text { Actions are being taken to help ensure a } \\
\text { better world for generations to come by } \\
\text { trying to create zero waste. }\end{array}$ & 4.51 & 1.50 & 3.50 & 3.17 & Neither \\
\hline $\begin{array}{l}\text { There is a policy on exchange and reuse } \\
\text { of plastic bags thereby increasing the life } \\
\text { span of the products so that they don't } \\
\text { wind up in trash bags. }\end{array}$ & 3.50 & 1.00 & 3.00 & 2.5 & Neither \\
\hline $\begin{array}{l}\text { Retail establishments have been able } \\
\text { to reduce both operating costs and the } \\
\text { environmental impact of its business } \\
\text { practices. }\end{array}$ & 5.00 & 2.25 & 3.50 & 3.58 & Effective \\
\hline Average & 4.06 & 1.72 & 3.58 & 3.12 & Neither \\
\hline
\end{tabular}

Table 4: Level of Effectiveness of the Use of

Non-Biodegradable Packaging Methods amongst Retailing Establishments in Kingdom of Bahrain in Terms of Environmental Sustainability; source: Original Research

On average, the respondents rated neither with a mean score of 3.44 that the process of creating environmental sustainability by retail establishments is neither effective nor ineffective. With an adjectival rating of effective, the respondents (managers, supervisors of supermarkets and consumers) perceived that only retail establishments like supermarkets have been able to work on preserving the capability of the environment to support human life by using biodegradable bags and cotton bags and by promoting the sale of alternative bags.

All decisions taken by these big stores place stress on how to reduce negative impacts on the environment and, therefore, promote environmental sustainability. Actions are being taken by these big stores to help ensure a better world for generations to come by trying to create zero waste through providing re-cycling collection points for different types of wastes.
The study found that the supermarkets are encouraging the customers to reuse the biodegradable plastic bags, thereby increasing the life span of the products so that they do not wind up in trash bags. However, the respondents rated as neither effective nor ineffective the efforts made by The cold stores are providing the plastic bags free of charge and that may be the reason that is causing consumers to go for this kind of bag instead of buying and using alternative bags which are costlier The cold stores are not bothered about having any form of plastic carrier bag recycling at the store or using or promoting any recycling programs as there is no penalty for selling them. Moreover, the majority of the consumers who visit cold stores regularly do not have enough knowledge related to environmental benefits in order to prompt use of alternative bags.

As noted elsewhere (Njeru, 2006), urban environmental problems are likely results from cultural process. Upon closer analysis, it is evident cold stores in creating environmental sustainability. the intricately intertwined economic, political an 
The Usage of Non-Biodegradable Packaging Materials, Recycling Strategies and Impacts on the Environment: the Case of Bahrain that the ecological process involved can lead to the transformation of the urban environment while the economic, political and cultural processes have the tendency to create, recreate and maintain an unequal and unjust urban environment.

As the production and use of plastic has increased over the years in Bahrain, a large amount of plastic waste has accumulated in the environment. As a durable material, it is also persistent. Also, the study found that recycling strategies adopted are minimal and, hence, the actual amount of plastic waste produced remains roughly the same and adds to existing waste.

Again, the study found that since it is not recycled or recovered, most plastic waste is disposed of in landfill sites where, although not visible, items come to the surface as debris. In addition, the conditions within landfill may cause the chemicals contained within plastic to become more readily available to the environment. This is a particular concern in a small island like the Kingdom of Bahrain, where landfill management is not as closely monitored as in the $\mathrm{EU}$, for example.

In terms of the degradation of plastic carrier bags, a study examined compostable and oxobiodegradable plastics (which contain metal salts to speed up the degradation process) and found that compostable plastics were completely lost from the wooden platforms to which they were stapled within 16 to 24 weeks, whereas 98 per cent of the oxo-biodegradable plastic remained after 40 weeks (Brine \& Thompson, 2010). Increasing the could have unintended negative impacts in some cases due to the possibility that plastic does not fully degrade in the marine environment and could therefore speed up the creation of micro plastics.

Better methods to isolate micro plastics from surface waters, sediments and organisms are needed, as well as research methods that produce comparable data across different studies. Where possible, micro plastic measurements could be added to existing and ongoing plankton surveys, especially in coastal areas (Arthur, Baker \& Bamford, 2009). At the Joint Group of Experts on the Scientific Aspects of Marine Environmental Protection (GESAMP) workshop on this subject, there was a call for a taxonomy of plastic particles in terms of size, shape, density, chemical composition and properties as well as the age of particles (Bowmer \& Kershaw, 2010). This could be incorporated into more specific standards that define Good Environmental Status in the Bahrain Marine Fisheries Services Departmen (MFSD) and help develop guidelines on sampling and reporting.

Although there is little research on the specific impacts of plastic waste on land-based wildlife, there is concern that incorrectly managed landfills could lead to either the escape of plastic waste or the escape of landfill leachate containing the chemicals associated with plastic. In addition, unofficial recycling methods, particularly in developing countries, can cause the release of chemicals into the environment, for example, the burning of plastic coated wires to extract metal A study conducted by UNEP (2006), claims that plastic waste has caused the death of up to a million marine mammals and countles fish through various impacts. Studies on mussels (e.g. Browne, Dissanayake \& Galloway, 2008) indicate that micro plastics are translocated from the gut to the circulatory system within three days and then persist in circulation for over 48 days. The research also found a higher number of smaller particles $(3.0 \mu \mathrm{m}$ microspheres) in the circulatory fluid than larger particles ( $9.6 \mu \mathrm{m}$ microspheres) which indicates that these smaller particles have greater potential for accumulation in tissues of organisms.

A lesser-known impact that could result from ingestion, entanglement and inadequate waste management is the impact of chemicals on human and ecosystems, either contained in plastic or transported by plastic waste. Plastic is not inert but contains several chemicals with toxic potential. It also has the potential to transport contaminants. Although much is known about the impact of actua chemicals themselves, there still remain many questions about the role of plastic and plastic waste in exposing humans and wildlife to these chemicals. composed of repeating subunit or monomers and some of the major plastics (fo example, PVC and polystyrene) have been foun to release toxic monomers linked to cancer an reproductive problems (Marcilla, Garia \& GarciaQueseda, 2004). Often, during plastic production, polymerisation reactions are not complete and

The Usage of Non-Biodegradable Packaging Materials, Recycling Strategies and Impacts on the Environment: the Case of Bahrain

the unreacted monomers can be found in the final material. Polymers can also be broken up into monomers by heat, UV radiation, mechanical action and other chemicals. A study conducted in the EU (Lithner, Larsson \& Dave, 2011) compiled an environmental and health hazard ranking of 55 polymers based on the hazard classifications of their component monomers from the EU classification, labelling and packaging regulations. Thirty-one of these were made from monomers that belong to the two worst hazard levels and many have high levels of global annual production. The study indicated that PVC should receive extra attention because it contains a carcinogenic monomer and is produced globally in large quantities.

4. Conclusions and Recommendations

The respondents strongly agreed that there is high usage of non-biodegradable packaging methods in the Kingdom of Bahrain but the frequency of reusing a bag is not that high. Regarding recycling strategies adopted by the two kinds of retail establishments, the respondents perceived that supermarkets are doing much better. In terms of the level of effectiveness, the respondents perceived that recycling strategies adopted as well as processes to bring about environmental sustainability by the retail establishments are neither effective nor ineffective in reducing plastic and creating sustainability in the country. In terms of customer satisfaction, the study found that the consumers who make regular visits to supermarkets perceived with a mean of 3.86 that actions are being taken to help ensure a better world for generations to come by trying to create zero waste. The study found that the major problems the retail establishments are facing are in terms of implementing recycling strategies and creating environmental sustainability; misuse and improper disposal of plastic bags, as well as inadequate levels of governmental support to promote reusable packaging methods,

There is a cost factor in the implementation of reusable packaging methods. Although there seems to be a small number of stores and consumers participating in the recycling programmes, the researcher suggests adopting policies and programmes to increase the awareness of the benefits and programs available for plastic carrier bag recycling. Instituting policies and programs to increase recycling efforts should be tailored to the participants and stakeholders for best success rates. The findings presented here suggest more may need to be done to increase environmental awarenes and stress the importance of plastic bag recycling. There is a need for scientists to express 'damage' in terms that can be easily understood by the genera public. Where resources are limited, it will be important to focus on policies that deliver benefits to the largest proportion of the population on the most important sociological and health issues an micro-plastics might fare better in this regard when considered as a subset of the marine litter problem (Browne, Dissanayake \& Galloway, 2008). Plastic waste prevention is preferable to clean-up, which is very difficult to implement. Prevention can work at the level of production of plastic in terms of redesigning products to use less plastic, design for reuse and recycling and reduced packaging material. For these to be successful interventions, there may need to be a value placed on disposable products to encourage their reuse and encourage manufacturers to design them for reuse and recycling. Prevention can also work at the level of plastic becoming waste with the use of targets, taxes and bans but these must be carefully implemented. Although prevention is priority, due to the amount of plastic waste already in the environment, clean-up initiatives must also continue. These can be combined with monitoring exercises and involve local communities an fishing communities, such as KIMO's Fishing fo Litter. Some, such as International Pellet Watch, can assess levels of POPs. With such a huge issue as plastic waste, citizen science is a good approach to cleaning up and monitoring, while also increasing awareness. Effective policy requires effective monitoring and the current state of plastic waste monitoring needs harmonization, which is being put into place by various guidelines on marine debris in general. The need of the hour is to focus on

Landfill management and waste managemen in the country;

Littering on land, the coastal zone and at sea;

The use of micro plastics for abrasion in products including cosmetics;

Shredding plastic waste (particularly on boats) to put in food waste;

Excessive use of plastic bags and packaging 
The Usage of Non-Biodegradable Packaging Materials, Recycling Strategies and Impacts on the Environment: the Case of Bahrai

- Use of additives that are a risk to health, especially Bisphenol A and some phthalates;

- Use of plastics that will degrade quickly but not completely, leading to increase in micro plastics i.e. oxo-degradable plastics.

Production of an excessive number of guidelines should be avoided as these would later require harmonization.

Monitoring can be embedded in more general marine debris initiatives as long as there are figures specifically related to plastic. Similarly, micro plastic monitoring can be performed alongside plankton sampling.

There is also a need for better education and awareness around plastic waste. Plastic footprints and labeling on products are possible but need the appropriate education to make them meaningful. Alongside this there could be labeling of products ditives. Banning of some harmful chemicals contained in plastic, such as Bisphenol A and some phthalates, has

\section{References}

Aldred. J. (2007). "Q and A Plastic Bags," The Guardian (February $28^{\text {th }}$ ), available at: http://www.guardian.co.uk/environment/2007/nov/13/plasticbags. pollution?gusrc=rss\&feed=society.

Arthur, C., Baker, J. and Bamford, H. (2009). Proceedings of the International Research Workshop on the Occurrence, Effects, and Fate of Micro plastic Marine Debris (September $9^{\text {th }}-11^{\text {th }}, 2008$ ). National Oceanic and Atmospheric Administration Technical Memorandum NOS-OR\&R-30.

Bowmer, T. and Kershaw, P. (2010). Proceedings of the GESAMP International Workshop on Micro Plastic Particles as a Vector in Transporting Persistent, Bio-Accumulating and Toxic Substances in the Ocean. GESAMP Reports \& Studies No. 8.

Brine, T. and Thompson, R.C. (2010). "Degradation of Plastic Carrier Bags in the Marine Environment," Marine Pollution Bulletin (60), 2279-2283. already occurred, but for others restriction may have to be voluntary. A harmonized industrywide effort is needed to communicate informatio about chemicals used in plastic, alongside public education about the chemicals.

Waste management is highly important in addressing the issues of plastic waste. The systems differ from country to country and region to region. Although international and European legislation exists, it requires better monitoring to ensure complete implementation. More specific legislation or clause within existing legislation relating to plastic waste could be considered. In terms of addes coxisting problems with plastic waste the identification of
plastic waste 'hotspots' may prove useful. Another approach is the identification and protection of species, habitats and human groups that are vulnerable to plastic waste and the chemicals associated with it. In general, there needs to be better integration of marine planning with terrestria planning.

Browne, M.A., Dissanayake, A. and Galloway, T.S. (2008). "Ingested Microscopic Plastic Translocates to the Circulatory System of the Mussel, Mytilus Edulis (L.)," Environmental Science and Technology, 42(13), 5026-5031

Ellis, S., Santner, S., Saab, A. and Watson, W. (2005) "Plastic Grocery Bags: The Ecological Footprint," available at: http://www.vipirg.ca/archive/ publications/pubs/student papers/05_ecofootprint_plastic_bags.pdf.

Hawkins, G. (2001). "Plastic Bags: Living With Rubbish," International Journal of Cultural Studies, $4(1), 5-23$.

Hay, L. (2010). "In Practice," Perspectives In Public Health,130(4), 153

Hopewell. J, Dvorak, R. and Kosior, E. (2009). "Plastics Recycling: Challenges and Opportunities," Philosophical Transactions of the Royal Society of Biological Sciences, 364, 2115-2126.

The Usage of Non-Biodegradable Packaging Materials, Recycling Strategies and Impacts on the Environment: the Case of Bahrain

Lajeunesse, S. (2004). "Plastic Bags,” Chemical and Engineering News, 82(38), 51.

Lewis, H., Verghese, K, and Fitzpatrick, L. (2010). "Evaluating the Sustainability Impacts of Packaging: the Plastic Carry Bag Dilemma," Packaging Technology and Science, 23, 145-160.

Lithner, D., Larsson, Å. and Dave, G. (2011). "Environmental and Health Hazard Ranking and Assessment of Plastic Polymers Based on Chemical Composition," Science of the Total Environment, 409, 3309-3324.

Marcilla, A., Garia, S. and Garcia-Queseda, J.C. (2004). "Study of the Migration of PVC Plasticizers," Journal of Analytical and Applied Pyrolysis, 71(2), 457-463.)

Ritch, E. Brennan, C. and Macleod, C. (2009). "Plastic Bag Politics: Modifying Consumer Behavior for Sustainable Development," International Journal of Consumer Studies, 33, 168-174.

Roach, J. (2003). "Are Plastic Grocery Bags Sacking the Environment?" National Geographic News (September $\left.2^{\text {nd }}\right), 2003$, available at: http://news.nationalgeographic.com/news/2003/09/0902 030902 plasticbags.html.

Smith, S. (2004). "Plastic Bags," Parliamentary Briefing No. 5/04, NSW Parliamentary Library Research Service.
United Nations Environment Programme (UNEP) (2006). "Ecosystems and Biodiversity in Deep Waters and High Seas," UNEP Regional Seas Reports and Studies No. 178 (Geneva: UNEP/ IUCN).

Waste and Resource Action Programme (WRAP) (2009). "Case Studies: Reducing Carrier Bag Use," available at: http://www.wrap.org.uk/downloads/Carrier_Bag_Case_Studies_22_Mar_111. b245ecdf.7362.pdf.

Waste and Resource Action Programme (WRAP) (2010). "Environmental Benefits of Recycling. 2010 Update," available at: http://www.wrap.org. uk/content/environmental-benefits-recycling.

Waste Resource Action Programme (WRAP) (2005). "Carrier Bag Usage and Attitudes: Benchmark and Target Market Study," available at: http:/ home2 btconnect.com/reusabags/pdf/CarrierBagUsage.pdf.

Waste Resource Action Programme (WRAP) (2015). "Carrier Bag Observational Research in England," available at: http://www.wrap.org.uk/ sites/files/wrap/Carrier\%20Bag\%20Observation$1 \% 20$ Research $\% 20$ in $\% 20$ England.pdf.

Williams, C. (2004). "Battle of the Bag: The World Ha Declared War on the Plastic Bag. What Did Thi Harmless Item Do to Attract Such Opprobrium? New Scientist, 183(2464), 30. 